\title{
Construction of Service System on Enterprise Alternate Innovation in Creative Industry Park
}

\author{
Bingfeng Liu" a * \\ ${ }^{1}$ School of Business Administration, JingDeZhen Ceramic Institute, Jiangxi Province, China \\ atxcf2000@163.com
}

\begin{abstract}
Keywords: Creative industry park; Business incubator; Business accelerator; Alternate innovation; Innovation service system
\end{abstract}

\begin{abstract}
An alternative is a lot of innovation park enterprise innovation mode, but also has its own characteristics, based on the alternating innovation as the logical analysis to study the alternation of innovation system of enterprises of creative industrial park, is conducive to the accurate positioning, rational judgment, guiding the construction of creative industry innovation system, and to provide scientific basis for the development of the policy and creative industry park. The creative industry park as the innovation model of the development of creative industries has become a new growth engine of national, regional and the city of new normal. From the connotation of service system on enterprise alternate innovation in creative industry park, discusses the forming mechanism of service system on enterprise alternate innovation in creative industry park, has studied the strategies of constructing on service system on enterprise alternate innovation in creative industry park.
\end{abstract}

\section{Introduction}

The rapid development of creative industry has become a reality in the era of globalization, the construction of creative industrial park is one of the basic pattern of the development of the industry, has received high attention in academic circles and government departments in different countries and regions. Creative innovation ability of enterprise growth based on the entrepreneurial process, cooperation, win-win cooperation. The park service to become the incubator and accelerator for key service organizations, "incubation acceleration" of two big functions complement each other, continue to strengthen, gradually evolved into the current development of the creative industrial park services ecological chain. In fact, whether it is the creative business incubator or accelerator, is the creative industry park's creative innovation organization, the two in space and infrastructure, the existence of the rationality and necessity of coupling docking. In this docking process, the different main body of incubator and accelerator in which constant innovation, according to a certain pattern of repeated alternately, the final completion of the process of enterprise innovation in the park, it is called the alternative innovation.

Therefore, alternating innovation is actually in the creative industrial park in different creative industries park enterprises subject to take different creative innovation ecological chain in different sectors, different process, complete creative ideas, creative production, creative R\&D, production, marketing, creative business services and other activities to alternate the way, realize the value of creative innovation, enterprise successful hatching, enhance the growth rate, and ultimately to the market. Alternate theoretical foundation for innovation from independent innovation, imitative innovation, cooperative innovation, two innovation, open innovation, collaborative innovation mode, but not exactly the same; especially in some emerging industries, such as creative industry, appeared in the new innovation mode, this innovation is different from the characteristics of creative enterprises assume their respective different creative work, at the same time, through the activities of complementary strengths among the subjects to complete before cannot be completed, equal and alternating innovations in different subject status of each division and win-win coexistence. Creative industrial park in the relative concentration of the space in a collection of many different types of creative enterprises, the characteristics of this innovation is particularly evident. In the park, enterprise 
incubation acceleration module has a plurality of alternating innovation activities marked: creative activities completed can be decomposed into different processes; it is still in the incubation stage of accelerating, creative innovation activities are extremely complex and knowledge intensive creative work, with higher risk and uncertainty; creative innovation different from other innovation activities, inspiration, perception of life, creative theory strong dependence, especially creative talents is very important; property rights of enterprises identified in the creative innovation activities and value distribution of the core position of the ecological chain. Judging from the above characteristics, with the development of creative industrial park, it is inevitable that the alternation of innovation in the incubation acceleration module.

Based on this, the purpose of this paper is to explore the creative industrial park enterprises in alternate innovation and other industrial park enterprises have different characteristics, what are the general rules, how to carry out the application. Especially can be used in analysis of the conclusions, provide a reference for enhancing the innovation performance of creative industries, in order to effectively carry out the Park incubator, accelerator innovation resources, provide the basis for optimal allocation of state implementation.

\section{The Formation Mechanism of the Innovation Service System of Creative Industrial Park Enterprises}

The innovation of the enterprises in the creative industry park has its own development law. Different from other industries, creative industry emphasizes the independent intellectual property rights, which belongs to the content of intensive industry typical, for independent innovation of enterprises are higher, constitute the main body is more complex, especially focusing on the culture, copyright and content of enterprise. Creative industry is the cultural industry of high-end form, the generalized that the creative industry is a concept of the ideological level, the high-end industry, not limited to the field of culture, with particular emphasis on science and technology, culture and the creation of additional values. Creative industry is an innovative part of the development of cultural industries, so the formation mechanism of enterprise innovation in the creative industry park can be answered by the characteristics of the industry itself.

The enterprises in the park in the creative process of innovation, necessarily involves the collection, collation, analysis, analysis and use of large amounts of information. In the era of big data, creative enterprises involved in the number of creative information has a very large, complex sources, the rapid flow of value and a broad range of features and so on. Creative enterprises in the park are Small and micro businesses, smaller volume, distinctive but flexible transformation, whether it is in state or in a state of accelerated hatching enterprise, to achieve entrepreneurial success, we must rely on a large number of possession of creative information, many creative enterprises to gain commercial success from the use of information, it is must alternate rely on the synergy with other subjects.

On the other hand, alternate creative enterprises park innovation can be divided into several continuous process, acquisition, processing and analysis of information from the creative, creative ideas, creative development, finally completed the construction of innovative business model, to promote business success. In these processes, due to the division of labor, there will be different types of creative enterprises. One is the creative market enterprises, such enterprises for processing, processing of creative information and even create new ideas, and promote the market to achieve the creative value, the founders and employees are often experts or scholars with creative genius. The creative skills of enterprises, such enterprises can analyze the creative information, but the lack of the ability of creative business [2]. Three is a creative consulting firm, these companies have a lot of creative information reserves, and constantly search for new information from the market, but the lack of creative and innovative ability. In the era of creative economy and big data, creative industrial park enterprises to achieve success, we must rely on different types of enterprise innovation, fewer companies can have information, creative and commercial capacity. 
The ultimate goal of constructing alternative park Innovation service system is to promote high quality innovation activities, while the activity of value creation to commercialization and industrialization to promote the development of enterprises in the market, profit growth and social economy and culture. Park service system development today, related diversification situation has been formed, different types, stages and characteristics of the enterprise has a different level of demand, to meet these requirements, relying on incubation or acceleration state of individual enterprises has been difficult to complete, creative enterprises as innovation intensive high growth organization, requires the park create professional, the difference of the service platform. The emergence of alternative innovation model, just to meet the needs of enterprise innovation services. In this mode, starting from the innovative service creative projects, according to the specific orientation of innovation and creative enterprises, and accelerate the incubator service system can realize collaborative sharing, docking interaction, park to provide enterprises with high quality, for the service of entrepreneurship and innovation [3].

\section{The Construction of Creative Industrial Park Business Innovation Service System Strategy}

The construction of innovative service system of creative industrial park is the core content of promoting the rapid development of creative industrial park, and also the breakthrough of creative industries in our country, which is the fundamental requirement for the development of the leap type. First of all, to the creative industrial park Service resources to effectively integrate, standardize the innovation service system. The new media animation game industry as the core, to promote cross industry, cross sectoral, cross sectoral network of divergent type docking coupling hatch-accelerated alternative innovation platform. This platform for the development of animation and creative enterprises to build a full participation, integration and docking of alternative innovation service system, and effectively promote the Chinese production of animation and the internationalization of the game. Secondly, because the incubation and acceleration module are innovative service supply system, has some common characteristics and service level, in order to avoid duplication of development, should actively explore and form the coupling mechanism of enterprise alternating innovation, effectively guide the rational flow of high-quality resources, improve the efficiency and competitiveness of service innovation park. At present, Wuhan East Lake development zone is the full implementation of animation industry development planning, and the basic form of the overall layout of a zone of alternating innovation, such as the hatching of the river through animation, metropolis still diffuse a large number of outstanding creative enterprises, extremely rapid development momentum. Third, the overall planning should focus on internal and external layout, based on regional characteristics. The construction of the service system of creative industrial park should have international vision and international standards to regulate the service, and to highlight the advantages of domestic and regional characteristics. In addition, the creative industrial park business alternative innovation service system should also be based on the actual situation surrounding and similar park development strategy, the competitive region to effectively plan, to avoid the homogenization of services and excessive competition. At present, Jingdezhen Tao- Xichuan international ceramic cultural and creative industry park to give full play to the Jingdezhen Millennium ceramic culture, to create a creative era, to build a strategic platform, creating a palace of art "strategic concept and global vision, through the practice of the national strategy of Poyang Lake ecological economic zone planning," one axis and four pieces of six "the factory in order to undertake the alternation of innovative service system, the construction of cultural and creative industry base, including ceramic creative design center, tourist center, ceramic culture and ceramic culture exhibition and exchange center, trading center, ceramic education and information media center platform world class art creative exchange park.

The basic purpose of building a creative industrial park service system is to promote the enterprise to create more value, to achieve effective business incubation, to improve the growth rate of enterprises, and ultimately to improve the competitiveness of the park. In today's big data, cloud computing era, 
whether it is in the incubator or accelerate the module, it is bound to reflect the ability to transform the enterprise with different knowledge [4]. The growth of these main requirements of the park service process and innovation process is consistent, that is to say, the service process and innovation process to be effective docking in order to play its fundamental role. The park should establish a rational mechanism for the process of innovation based on the subject, type, scope and mutual relationship of the creative enterprises. As mentioned before, alternative innovation and other innovative models have both in common, there are different points. It should be noted that, although the creative enterprises involved in the alternative innovation are based on the results of the previous link to carry out their own creative activities, but not the results of other subjects to carry out a simple process.

In the process of enterprise's alternate innovation service, the process of the enterprise is in a dynamic loop system, the hatching and accelerating module will be changed, the boundary of the module will be blurred, and from chaos to order. The process of docking mechanism comprises a plurality of different stages: (1) the exploration stage: individual creative enterprises are more and more emphasis on the characteristics of creative resources become the one and only, division of labor is increasingly clear, service organizations showed typical standardization; (2) gradually formed stage: according to market demand, the initial formation of alternating innovation module, service standards the service system, and gradually build; different incubation acceleration module self-perfection and single docking, a small coalition in the park began to appear, some creative enterprises gradually began to grow, innovative services ecological chain formed; (3) the dynamic docking stage into the module, the combination of different modules and hatching from the chain to accelerate system transformation network, service innovation network gradually formed and perfect [5].

In the alternate process of innovation activities docking, the evolution of creative industrial park enterprises is the mutual influence, interaction and reciprocal causation; that is to say, through co evolution, a creative enterprise innovation by alternating the advantage gained by partners will increase its competitiveness, at the same time to the competition pressure, promote the improvement of competitors [6].

Coevolution can effectively promote the dynamic docking hatch, acceleration module, the positive effect of security in creative enterprises in the interaction of continuity and amplification, negative effect is suppressed and weakening, help the two sides to strengthen cooperation, enhance trust. In addition, through the continuous cycle of the process of docking, the formation of a positive balance of mutual benefit relationship in the creative industrial park, to reduce the occurrence of zero sum game behavior.

In particular, in the creative industrial park, due to the relatively close proximity of the geographical location, the park business interaction than non-park enterprises more frequently, the impact is more far-reaching. Of course, in order to achieve co evolution, enterprises cannot rely on natural to adapt to environmental change, must adopt different ways to promote, for example, based on dislocation management, ecological niche differentiation and value innovation, resource expansion etc. The longitudinal guide active and collaborative network, promote the cultivation of mutually beneficial symbiotic relationship between enterprises in the park, especially to play a leading role in the core enterprises, these enterprises will bring change to other enterprises produce favorable changes in positive selection pressure, help other enterprises, guarantee the alternating innovation service system of the enterprises in the park healthy growth and sustainable development.

\section{Summary}

With the rapid development of creative industries, industrial park projects across the country continue to be launched, creative business incubators and accelerators are in various forms of rapid growth, a strong impetus to enhance the competitiveness of the industry. At the same time, the innovation of creative industrial park has distinctive characteristics different from other industries, in order to avoid duplication and waste of resources, creative industry park should learn from the successful experience abroad, the effective allocation of service innovation resources, build enterprise innovation alternative 
service system, follow the overall planning, layout and process of effective docking, co evolution the strategy, starting from the service of the national strategy and regional economic point of view, to improve the level of innovative services.

\section{References}

[1] Hawkins, J. The Creative Economy: How People Make Money from Ideas. Allen Lane, the Penguin Press. 2001.

[2] Richard Florida. The Rise of the Creative Class. New York: Basic Books, 2002.

[3] Pratt. Creative Cities: the Cultural Industries and the Creative Class. Human Geography, 2008, Vol.90,pp.102-117.

[4] Agenor. Health and Infrastructure in a Model of Endogenous Growth. Journal of Macroeconomics, 2008, Vol.30, No.4, pp.1407-1422.

[5] Kong, Gibson et.al. Knowledges of the Creative Economy: Towards a Relational Geography of Diffusion and Adaptation in Asia. Asia Pacific Viewpoint, 2006, Vol.47, pp.173-194. 